University of Nebraska - Lincoln

DigitalCommons@University of Nebraska - Lincoln

\title{
A Simulation Based Experiment For Comparing AMHS Performance In A Semiconductor Fabrication Facility
}

\author{
Gerald Mackulak \\ Arizona State University at the Tempe Campus \\ Paul Savory \\ University of Nebraska at Lincoln, psavory2@gmail.com
}

Follow this and additional works at: https://digitalcommons.unl.edu/imsefacpub

Part of the Industrial Engineering Commons, Operational Research Commons, and the Other Operations Research, Systems Engineering and Industrial Engineering Commons

Mackulak, Gerald and Savory, Paul, "A Simulation Based Experiment For Comparing AMHS Performance In A Semiconductor Fabrication Facility" (2002). Industrial and Management Systems Engineering Faculty Publications. 57.

https://digitalcommons.unl.edu/imsefacpub/57

This Article is brought to you for free and open access by the Industrial and Management Systems Engineering at DigitalCommons@University of Nebraska - Lincoln. It has been accepted for inclusion in Industrial and Management Systems Engineering Faculty Publications by an authorized administrator of DigitalCommons@University of Nebraska - Lincoln. 


\title{
A SIMULATION BASED EXPERIMENT FOR COMPARING AMHS PERFORMANCE IN A SEMICONDUCTOR FABRICATION FACILITY
}

\author{
Gerald T. Mackulak, Ph.D. \\ Department of Industrial Engineering \\ Arizona State University \\ Paul Savory, Ph.D. \\ Department of Industrial and Management Systems Engineering \\ University of Nebraska
}

ALL CORRESPONDENCE AND CORRECTIONS SHOULD BE ADDRESSED TO:

Mailing: $\quad$ Dr. Gerald Mackulak $\quad$ Phone: (480) 965-6904

Industrial Engineering E-Mail: mackulak@asu.edu

PO Box 875906

Arizona State University

Tempe, AZ 85287-5906 


\title{
A SIMULATION BASED EXPERIMENT FOR COMPARING AMHS PERFORMANCE IN A SEMICONDUCTOR FABRICATION FACILITY
}

\begin{abstract}
As the cost and complexity of constructing a semiconductor fabrication facility increases, responsive tools are needed for designing and planning its operations. Discrete-event simulation paired with design of experiments is an effective combination. This article demonstrates how simulation in combination with design of experiments is used to compare the intrabay layout of two automated material handling systems. The difference in stocker robot utilization, number of vehicle moves per hour, and average delivery time for the two intrabay layouts will be compared using a fractional factorial experimental design. The study demonstrates that the distributed storage option is preferable for maximizing manufacturing performance. Although the scope of this effort was restricted to a single situation, the solution procedure has general applicability as a tutorial for practitioners.
\end{abstract}

\subsection{Introduction}

One of the key components in designing a semiconductor fabrication facility is defining the layout and operation of the automated material handling system (AMHS). As the semiconductor industry moves towards $300 \mathrm{~mm}$ manufacturing, design of the AMHS is significant since not only will interbay movements be automated, but due to the size and weight of the wafer cassettes, intrabay movements will also be automated. Having the AMHS be the bottleneck of the factory's production is unacceptable if high throughput and low cycle times are desired. Appropriate analysis techniques and tools are needed to carefully explore and plan the operation of an AMHS [1]. 
G.T. Mackulak and P. Savory (2002), "A Simulation Based Experiment For Comparing AMHS Performance In A Semiconductor Fabrication Facility,” IEEE Transactions on Semiconductor Manufacturing. Volume 14, No. 3, pp. 273-280.

Discrete-event simulation has become one of the most important operations research techniques for analyzing a manufacturing system [2]. It's uses range from comparing alternative system designs to answering capacity and feasibility questions. In comparison, experimental design is an approach for systematically comparing a set of scenarios and testing the statistical significance between their results. An effective combination is to create a discrete-event simulation model of a system and then use experimental design to compare the results from running the model under varying conditions. The resulting analysis will provide decision makers with insight into the options available and the impact of each on production.

The remaining sections of this paper demonstrate using discrete-event simulation with experimental design for comparing two AMHS systems. The difference in stocker robot utilization, number of vehicle moves per hour, and average delivery time for two different intrabay layouts, distributed storage versus central storage, on an AMHS delivery system will be compared. Section 2 describes the two intrabay layouts. Section 3 outlines the experimental design. Section 4 discusses the simulation model development and output analysis. Section 5 presents the results for the distributed storage system. Section 6 discusses the results for the central storage system. Section 7 summarizes the analysis, compares the two intrabay layouts, and offers some concluding remarks.

\subsection{Intrabay Layouts}

The two intrabay layout configurations are presented in Figure 1. The length of the bays were initially 100 feet. This is in accordance with the recommendations of the International 300mm Initiative [3]. The total length of the bays for the central storage system was modified to be 120 feet as a result of inline rotating devices being added to the layout. The initial number of 
G.T. Mackulak and P. Savory (2002), "A Simulation Based Experiment For Comparing AMHS Performance In A Semiconductor Fabrication Facility,” IEEE Transactions on Semiconductor Manufacturing. Volume 14, No. 3, pp. 273-280.

tools for the distributed storage system is 20 (10 on each side of bay), and 40 for the central storage system (20 in each bay). During the experimental analysis, when the number of tools is increased, the bay length is proportionally increased.

In the distributed system (Figure 1a), one stocker serves one intrabay of tools, while in the central storage system (Figure 1b), one stocker serves both bays of tools in the intrabay. The distributed storage system uses one stocker per intrabay. In comparison, the central storage system requires only one stocker for multiple bays (this study uses one stocker per two bays). Furthermore, the distributed layout is such that the bays are connected at certain points so that product can transfer from one bay to the next without having to go through the stocker-interbay interface point.

\section{< Figure 1 Approximately Here >}

A robot cycle is defined as the movement of the robot from its existing unloaded position to the point of pickup, the loading of the item, and the subsequent delivery of the item to its destination. The reverse set of operations would also constitute a robot cycle. Figure 2 highlights the four move types which are considered single robot cycles: (1) Movement from the interbay system input point to the stocker shelf; (2) Movement from the stocker shelf to the intrabay system pickup point; (3) Movement from the intrabay system drop-off point back to the stocker shelf, and (4) Movement from the stocker shelf back to the interbay pickup point.

\section{< Figure 2 Approximately Here >}

The number of robot cycles per move is a function of the number of bays supplied by a single stocker. Obviously the robot stocker cycle time has an impact on the maximum number of bays that can be handled by a single stocker since robot utilization will eventually become the system limiting factor. 
G.T. Mackulak and P. Savory (2002), "A Simulation Based Experiment For Comparing AMHS Performance In A Semiconductor Fabrication Facility,” IEEE Transactions on Semiconductor Manufacturing. Volume 14, No. 3, pp. 273-280.

Assuming that product can go directly from bay one to bay two in the central storage system eliminates half of these robot move cycles. If we assume that tool storage is currently not available, we still save two robot cycles per movement by using the central storage system since the moves in and out of the interbay system (between bays) are eliminated. Regular operation in the distributed system requires all four robot moves. The difference in the centralized storage layout is that robot moves 3 and 4 are not needed since the lot is traveling to the next bay on the same vehicle (i.e., the required robot moves are reduced to 50\% compared to regular operation). If storage is not available at the next tool location, the product will need to return and be stored in the stocker.

\subsection{Experimental Design}

The goal of this study is to determine the number of vehicles moves, stocker utilization, and the average delivery times for the two different layouts. The average delivery time will be the key measure for determining AMHS performance. Delivery time is defined to begin when the lot in a stocker makes the request for a transporter and ends only when it has been transported and delivered to its destination (i.e., the next station in its visitation sequence). Stocker utilization is defined as the average load of the stockers over the total capacity. In order to avoid having to use alternative stockers, a $0.6-0.7$ load/capacity ratio is assumed. Finally, it is assumed that the lot arrival rate remains constant.

To determine the functional differences between the central and distributed storage systems, it is necessary to define a set of varying conditions under which the simulation model will be run. The first task to accomplish this involves identifying those factors that are believed to impact the delivery time profiles of both system. Following a review of industry practices and 
G.T. Mackulak and P. Savory (2002), "A Simulation Based Experiment For Comparing AMHS Performance In A Semiconductor Fabrication Facility,” IEEE Transactions on Semiconductor Manufacturing. Volume 14, No. 3, pp. 273-280.

team member semiconductor experience, it was determined that five factors can significantly impact system performance. These five factors include: (1) the number of storage locations each containing a single front opening unified pod (FOUP) per input/output port (this concept relates to the queuing space available at each I/O port), (2) tool processing time, (3) speed of the overhead hoist vehicles (OHVs), (4) stocker cycle time, and (5) total number of tools employed in each bay.

With the identification of the important factors, it is next necessary to develop a suitable range for each. The ranges are based on the guidelines outlined by the International 300mm Initiative [3]. The five experimental factors and the range of parameter values are summarized in Table 1.

\section{< Table 1 Approximately Here >}

Next, it is necessary to determine an efficient experimental design for investigating the effects of the factors for each of the two systems. Since one of the objectives of the study is to determine which of the five parameters significantly contributes to the resulting delivery time performance in each system, it is assumed that a one-quarter fraction of a five-factor factorial experiment will be suitable for the investigation of both storage system strategies [4]. The $2^{5-2}$ resolution III design requires eight simulation replications for each scenario and returns a detailed estimation of the main system effects. Unfortunately, since this experimental design results in the aliasing of two-factor interactions with main effects and other two-factor interactions, the results of the initial experiments will not be suitable for the estimation of all interactions between parameters [4]. However, it is hypothesized that only a subgroup of the five factors will be revealed as being significant to the performance of either system. 
G.T. Mackulak and P. Savory (2002), "A Simulation Based Experiment For Comparing AMHS Performance In A Semiconductor Fabrication Facility," IEEE Transactions on Semiconductor Manufacturing. Volume 14, No. 3, pp. 273-280.

The $2^{5-2}$ experimental design will be augmented with a single center replication in order to provide an estimate of curvature due to the potential presence of quadratic effects. Prior team experience in semiconductor fabrication suggests that such quadratic effects will range from nominal to non-existent. The inclusion of a single center point in each of the simulation experiments will provide a necessary check to this experimental design assumption. If present, further simulation experiments involving additional replications may prove to be necessary. However, the presence of a minor amount of curvature may be handled by an appropriate transformation of the response variable [4].

\subsection{Simulation Model Development and Output Analysis}

Models for both of the bay layouts were built using proprietary AutoMod simulation models of a major AMHS vendor. Using these models, which are near $100 \%$ emulators of the actual vehicle routing and control logic, ensured accurate results while minimizing time on model creation, verification, and validation. For each scenario of the experimental design, the average delivery time, the average number of vehicle moves, and the robot utilization was collected and stored in a data file as an hourly average. Each scenario required approximately 25 minutes of run time. Overall, over 250 hours of computer time was needed to run all the simulation scenarios.

The output from each of the nine simulation replications conducted for each system is analyzed to provide an estimate of the average values of each of the three response variables. The statistical program Design-Expert is used to appropriately analyze the results. A half normal probability plot is used to aid in the determination of significant effects with regard to each of the three response variables. The resulting half normal probability plots for each system are 
G.T. Mackulak and P. Savory (2002), "A Simulation Based Experiment For Comparing AMHS Performance In A Semiconductor Fabrication Facility,” IEEE Transactions on Semiconductor Manufacturing. Volume 14, No. 3, pp. 273-280.

displayed in Figures 3 and 4. Factors not on the plot line indicate they have a significant impact on the response variable.

\section{< Figure 3 Approximately Here > \\ $<$ Figure 4 Approximately Here $>$}

\subsection{DISTRIBUTED STORAGE SYSTEM}

The results from the simulation experiments conducted on the distributed storage system are presented in Table 2. Based on the estimates calculated for each response variable in addition to the corresponding half normal plots (Figure 3), the significant effects were chosen for inclusion in the regression models of the simulation data. The average delivery time model includes the vehicle speed and the number of tools in the bay. Tool process time is found to be the only significant effect with regard to the robot utilization response. Finally, the tool process time and the number of tools in the bay are the significant effects employed in the construction of the regression model concerning the vehicle moves per hour response.

\section{< Table 2 Approximately Here >}

Tables 3 - 5 show the analysis of variance and t-tests of model coefficients for the three response variables. To remove a mild degree of curvature in the response variable, both the models for the average delivery time and vehicles moves per hour require transformations in the response [4]. The average delivery time model involves a natural log transformation on the response while the vehicle moves per hour model fits the data to the inverse of the response. The regression models determined for each response variable are also provided in Tables $3-5$. All three regression models provide suitable fits to the experimental data with regard to the model Fvalues as well as the resulting adjusted $\mathrm{R}^{2}$ values. In addition, the t-tests on all of the regression 
G.T. Mackulak and P. Savory (2002), “A Simulation Based Experiment For Comparing AMHS Performance In A Semiconductor Fabrication Facility,” IEEE Transactions on Semiconductor Manufacturing. Volume 14, No. 3, pp. 273-280.

coefficients in each model provide p-values well below the five percent level. Analysis of the residuals for each model indicates no major violation of the assumptions of normality and equal variance in the model errors.

\section{< Table 3 Approximately Here > \\ < Table 4 Approximately Here > \\ < Table 5 Approximately Here >}

Figure 5 presents the response surface for the average delivery time. The average delivery time experiences a notable increase with an increase in the number of tools in the bay while the response slightly decreases with an increase in vehicle speed. These results are intuitively correct in that an expanded number of tools employed per bay will serve to increase the distance traveled within the bay while an increased track speed might serve to promote congestion within the system.

\section{< Figure 5 Approximately Here >}

The main effect plot for the robot utilization response is provided in Figure 6. The simulation results appear reasonable in that a decrease in the required tool process time would allow a greater number of FOUPs to be processed in a given amount of time. This increase in stocker demand would certainly result in increased robot utilization as displayed in the main effect plot.

\section{< Figure 6 Approximately Here >}

Figure 7 illustrates the response surface observed for the vehicle moves per hour. Decreasing the tool process time at the low level of the number of tools in the bay results in a minor increase in the response. Vehicle moves per hour is dramatically increased by decreasing the tool process time at the high level of the number of tools in the bay. It is assumed that the 
G.T. Mackulak and P. Savory (2002), "A Simulation Based Experiment For Comparing AMHS Performance In A Semiconductor Fabrication Facility,” IEEE Transactions on Semiconductor Manufacturing. Volume 14, No. 3, pp. 273-280.

response is impacted in such a manner due to the excessive demand placed on the AMHS as a result of decreasing the tool process time within a bay of extreme distance. As such, the material handling vehicles are required to perform an increased number of moves per hour in order to meet demand.

\section{< Figure 7 Approximately Here >}

\subsection{CENTRAL STORAGE SYSTEM}

The results from the simulation experiments conducted on the central storage system are presented in Table 6. The significant effects are chosen for inclusion in the regression models based on the estimates calculated for each response variable in addition to the corresponding half normal plots (Figure 4). As in the case of the distributed storage system, the vehicle speed and number of tools in the bay are found to be the significant effects in regard to the average delivery time response. Unlike the distributed storage system, the significant effects determined for the robot utilization response includes not only the tool process time but also the stocker cycle time and the number of tools in the bay.

\section{< Table 6 Approximately Here >}

The results of the analysis of variance and t-tests of the model coefficients conducted for each of the three models chosen for the corresponding system responses are presented in Tables 7 - 9. All three models require the use of an appropriate transform on the response variable in order to either treat curvature in the underlying system or eliminate the existence of inequality of variance in the residuals [4].

As in the case of the distributed storage system, the average delivery time model requires the use of a natural log transformation on the response. The regression model developed for the robot utilization response employs the use of an inverse square root transformation. This is 
G.T. Mackulak and P. Savory (2002), "A Simulation Based Experiment For Comparing AMHS Performance In A Semiconductor Fabrication Facility,” IEEE Transactions on Semiconductor Manufacturing. Volume 14, No. 3, pp. 273-280.

compared to corresponding distributed storage scenario model where no transformation is required. Instead of an inverse transformation on the response as required for the distributed storage system, the central storage scheme needs an inverse one-quarter power transformation to treat curvature in the model for the vehicle moves per hour response. The three regression models for the central storage system all provide good fits to the experimental data with regard to the analysis of variance, $\mathrm{R}^{2}$ values, and t-tests on the coefficients. Analysis of the residuals indicates no major violations of the model assumptions for all three response variables.

< Table 7 Approximately Here >

< Table 8 Approximately Here >

< Table 9 Approximately Here >

Figures 8 - 10 show the response surfaces generated from the models developed for the average delivery time, robot utilization, and vehicle moves per hour responses. Like the distributed storage system, the central storage strategy experiences a notable increase in the average delivery time with increasing number of tools in the bay and a mild decrease in the response with increasing vehicle speed. In addition, the required number of vehicle moves per hour dramatically increases with decreasing tool process time at the maximum value of the number of tools in the bay. In terms of robot utilization, the response experiences an increase with decreasing tool process time. However, while the robot utilization in the distributed storage scheme is only affected by the tool process time, the same response in the central storage scenario is a function of not only the tool process time but also the stocker cycle time and the number of tools in the bay.

< Figure 8 Approximately Here >

< Figure 9 Approximately Here >

< Figure 10 Approximately Here > 


\subsection{Concluding Remarks}

The goal of this study was to present a simulation-based methodology for estimating semiconductor AMHS performance and secondly to quantify performance differences between distributed and centralized stocker layouts. The study uses a combination of alternative layout designs and design of experiment techniques to identify the factors that significantly impact average delivery time and continues by illustrating how this information can be used to infer system performance. The methodology is useful as a template for anyone attempting to perform a comparison of a semiconductor material handling system. In addition, the specific results for the modeled scenario offers insight and general guidelines for layout design.

Comparisons in this study were made over a realistic ranges of selected system factors (Table 1), which included queue space at I/O ports, tool processing time, AMHS vehicle speed, stocker robot cycle time, and tools in the bay. The simulation analysis was performed using a sophisticated and significantly detailed AMHS simulation model. Although there is an infinite number of possible factors that could have been altered, the five used in this study are the most significant and/or visible in most material handling studies. These five are also the factors that can have a major impact on the philosophy of the handling system design and final system cost.

The comparisons of this study were to explore whether centralized storage is preferable to distributed storage in terms of selected quantifiable performance metrics. We purposely did not perform a cost analysis since the costing of these systems has a high degree of variability depending on customer, volume, past purchase agreements, and specialized interface requirements. Our hope is that the presented analysis will provide incentives for others to further investigate performance differences of these approaches. Unfortunately, equipment vendors are 
G.T. Mackulak and P. Savory (2002), "A Simulation Based Experiment For Comparing AMHS Performance In A Semiconductor Fabrication Facility,” IEEE Transactions on Semiconductor Manufacturing. Volume 14, No. 3, pp. 273-280.

unlikely to share proprietary factors and costing information with an independent third party for such a comprehensive comparison to be conducted.

The conclusion of this study is that the average delivery time produced for the distributed system is strictly less than the value produced by the centralized system. This conclusion holds in spite of the fact that the centralized system requires significantly fewer robot cycles per move on the average. One must therefore conclude that although the robot cycles needed to move product are reduced, the impact of greater distances offset this advantage. In all cases, increasing vehicle speed improves performance, but not to the extent one might expect. For example, doubling vehicle speed did not significantly reduce delivery time. Common assumptions regarding vehicle speed tend to be opposite of this result. It is commonly assumed that performance is near linearly related to vehicle speed, while in actuality, blockage and routing play larger roles.

Comparing Figure 5 with Figure 8 shows that average delivery time is slightly higher for the central storage system. The delivery time for the distributed storage system varies from a low of 3.07 minutes to a high of 4.84 minutes. In comparison, the delivery times for the central storage system range from a low of 3.21 minutes to a high of 4.98 minutes. This difference, at the extremes, translates to about an average of eight seconds per move. Eight seconds a move may appear to be small, but if one considers that a typical semiconductor facility may require 500 moves per hour, the impact translates to a savings of one to two vehicles, given certain availability and utilization assumptions.

Figure 6 and Figure 9 compare stocker robot utilization. Again, the distributed storage system outperforms the central storage scheme. The robot utilization resulting from the distributed storage scenario ranges from 0.24 (when tool process time is at the high level) to 
G.T. Mackulak and P. Savory (2002), "A Simulation Based Experiment For Comparing AMHS Performance In A Semiconductor Fabrication Facility,” IEEE Transactions on Semiconductor Manufacturing. Volume 14, No. 3, pp. 273-280.

0.384 (when tool process time is at the low level). For the central storage scheme, robot utilization varies from a low of 0.17 (when the tool process time is at the high level, the stocker cycle time is at the low level, and the number of tools in the bay is at the low level) to a high of 0.52 (when tool process time is at the low level, the stocker cycle time is at the high level, and the number of tools in the bay is at the high level). Again, this study did not consider the sizing of the stockers which may further favor the distributed system. If the centralized stocker requires more storage locations because of the two bay service zone, the average robot cycle time will probably also increase, further increasing the centralized systems average delivery time. However, if cost is considered, the centralized stocker may have the advantage of using a single robot and subsequent lower cost.

The number of vehicles moves per hour can be compared with Figure 7 and Figure 10. For the distributed storage system, the low value is 21.05 moves per hour when the significant factors of tool process time and stocker cycle time are set at the high and the low levels respectively. Alternatively, the high value of vehicle moves per hour is 58.1 when tool process time is at the low level and stocker cycle time is at the high level. For the central storage option, the values range from 20.35 to a high of 59.81. Although vehicle moves per hour are typically quoted on AMHS designs, they have relatively little value to a steady state operation working at less than full capacity. If the design is adequate, the moves per hour will be approximately the same, regardless of the storage approach used. The centralized system should however require fewer robot cycles to conduct these moves. Though this study indicates that the tool-to-tool movements does not result in a reduction in average move times.

The comparison demonstrates that the distributed storage option is slightly preferable for maximizing manufacturing performance in terms of the three performance variables. This may 
G.T. Mackulak and P. Savory (2002), "A Simulation Based Experiment For Comparing AMHS Performance In A Semiconductor Fabrication Facility,” IEEE Transactions on Semiconductor Manufacturing. Volume 14, No. 3, pp. 273-280.

not be true for all systems since it depends on the performance values of the factors and the physical layout of the system. Although the scope of this effort was restricted to a two-bay problem, the solution procedure of combining discrete-event simulation with experimental design has general applicability to practitioners.

One must remember that simulation is non-optimizing, it only estimates the effects of a given operation policy. As such, there are two statistical problems associated with simulation studies: (1) the strategic problems concerned with the design of a set of experiments, and (2) the difficulties concerned with how each experiment is conducted. As we have demonstrated, if one combines discrete-event simulation with the techniques and tools of design of experiments, a practitioner can systematically simulate the impact of varying conditions on a system and correctly compare the results.

\section{ACKNOWLEDGEMENTS}

We wish to thank project team members: James David, Ernesto Galaz, Fredrik Malmgren, Joakim Yngve, Miki Fukunari, and Siroos Sokhan-Sanj.

\section{REFERENCES}

[1] T.J. Jefferson, D. Pillai, “Throughput analysis and Modeling of 300mm Intrabay Transport Vehicles”, in Proceedings of International Conference on Semiconductor Manufacturing Operational Modeling and Simulation, 1999, pp. 86-91.

[2] M.S. Lane, A.H. Mansour, and J.L. Harper, "Operations research techniques: A longitudinal update 1973-1988,” Interfaces, vol. 23, no. 2 , pp. 63-68, March-April 1993.

[3] E. Bass and J. Eddy, "Metrics for 300 mm Automated Material Handling (AMHS) and Production Equipment Interfaces”, Technology Transfer \# 97123416A-TR, International 300 mm Initiative, p. 13, December 12, 1997. 
G.T. Mackulak and P. Savory (2002), “A Simulation Based Experiment For Comparing AMHS Performance In A Semiconductor Fabrication Facility,” IEEE Transactions on Semiconductor Manufacturing. Volume 14, No. 3, pp. 273-280.

[4] D.C. Montgomery, Design and Analysis of Experiments, 4th ed: New York: John Wiley \& Sons, Inc., 1997. 


\section{Paper: “A Simulation Based Experiment for Comparing AMHS Performance in a Semiconductor Fabrication Facility”}

\section{Table Captions}

TABLE 1: Design factors and allowable ranges

TABLE 2: Experimental Results for the simulation of the distributed storage system

TABLE 3: Experimental analysis of the average delivery time response for the simulation of the distributed storage system.

TABLE 4: Experimental analysis of the robot utilization response for the simulation of the distributed storage system.

TABLE 5: Experimental analysis of the vehicle moves per hour response for the simulation of the distributed storage system

TABLE 6: Experimental results for the simulation of the central storage system.

TABLE 7: Experimental analysis of the average delivery time response for the simulation of the central storage system.

TABLE 8: Experimental analysis of the robot utilization response for the simulation of the central storage system.

TABLE 9: Experimental Analysis of the vehicle moves per hour response for the simulation of the central storage system. 
Table 1

\begin{tabular}{|c|l|c|c|c|}
\hline FACTOR & DESCRIPTION & UNITS & LOW & HIGH \\
\hline A & \# of FOUPs per I/O Port & Number & 1 & 5 \\
\hline B & Tool Processing time & lot/hour & 0.5 & 1.5 \\
\hline C & Vehicle Speed & feet/minute & 110 & 220 \\
\hline D & Stocker Cycle Time & Seconds & 13 & 18 \\
\hline E & \# Tools in Bay & number & 10 & 30 \\
\hline
\end{tabular}


Table 2

\begin{tabular}{|c|c|c|c|c|c|c|c|c|c|}
\hline \multicolumn{10}{|c|}{ DISTRIBUTED STORAGE SYSTEM } \\
\hline \multirow{2}{*}{\multicolumn{2}{|c|}{ Experimental Trial }} & \multicolumn{5}{|c|}{ Factor } & \multicolumn{3}{|c|}{ Response } \\
\hline & & A & B & C & $D$ & E & & & \\
\hline $\begin{array}{c}\text { Standard } \\
\text { Order }\end{array}$ & Run Order & $\begin{array}{c}\text { Number of } \\
\text { Foups per } \\
\text { /O Port } \\
(\#)\end{array}$ & $\begin{array}{c}\text { Tool } \\
\text { Process } \\
\text { Time } \\
\text { (lots } / \mathrm{hr})\end{array}$ & $\begin{array}{l}\text { Vehicle } \\
\text { Speed } \\
\text { (ft/min) }\end{array}$ & $\begin{array}{c}\text { Stocker } \\
\text { Cycle Time } \\
(\mathrm{sec})\end{array}$ & $\begin{array}{c}\text { Number of } \\
\text { Tools in Bay } \\
(\#)\end{array}$ & $\begin{array}{c}\text { Robot } \\
\text { Utilization } \\
\\
(\%)\end{array}$ & $\begin{array}{c}\text { Venicle } \\
\text { Moves pe } \\
\text { Hour } \\
\text { (moves/hr }\end{array}$ & $\begin{array}{l}\text { Average } \\
\text { Delivery } \\
\text { Time } \\
\text { (min) }\end{array}$ \\
\hline 1 & 5 & 1 & 0.5 & 110 & 18.0 & 30 & 0.432 & 43.112 & 4.516 \\
\hline 2 & 1 & 5 & 0.5 & 110 & 13.0 & 10 & 0.284 & 39.348 & 3.983 \\
\hline 3 & 8 & 1 & 1.5 & 110 & 13.0 & 30 & 0.215 & 29.760 & 4.681 \\
\hline 4 & 6 & 5 & 1.5 & 110 & 18.0 & 10 & 0.200 & 19.868 & 3.902 \\
\hline 5 & 3 & 1 & 0.5 & 220 & 18.0 & 10 & 0.394 & 39.344 & 2.874 \\
\hline 6 & 2 & 5 & 0.5 & 220 & 13.0 & 30 & 0.426 & 58.972 & 4.469 \\
\hline 7 & 7 & 1 & 15 & 220 & 13.0 & 10 & 0.144 & 19.856 & 2956 \\
\hline 8 & 4 & 5 & 1.5 & 220 & 18.0 & 30 & 0.298 & 29.752 & 3.952 \\
\hline 9 & 9 & 3 & 1.0 & 165 & 15.5 & 20 & 0.284 & 32.948 & 4.089 \\
\hline
\end{tabular}


Table 3

\begin{tabular}{|c|c|c|c|c|c|}
\hline \multicolumn{6}{|c|}{ Average Delivery Time } \\
\hline \multicolumn{6}{|c|}{ Analysis of Variance } \\
\hline Source & $\begin{array}{l}\text { Sum of } \\
\text { Squares }\end{array}$ & $\begin{array}{l}\text { Degrees of } \\
\text { Freedom }\end{array}$ & $\begin{array}{c}\begin{array}{c}\text { Mean Square } \\
\text { Error }\end{array} \\
\end{array}$ & F-Value & p-Value \\
\hline Model & 0.211839 & 2 & 0.10592 & 16.9176 & 0.0059 \\
\hline Curvature & 0.00294928 & 1 & 0.00294928 & 0.471061 & 0.5230 \\
\hline Residual & 0.0313046 & 5 & 0.00626092 & \multicolumn{2}{|c|}{$\therefore \therefore \therefore \therefore \therefore \therefore \therefore: \therefore$} \\
\hline Total & 0.246093 & 8 & \multicolumn{3}{|c|}{ 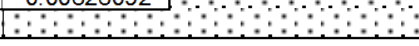 } \\
\hline \multicolumn{2}{|c|}{\begin{tabular}{|l|l|} 
& \\
R-Squared & 0871251 \\
\end{tabular}} & & & & \\
\hline Adj R-Squared & 0.819751 & & & & \\
\hline \multicolumn{6}{|c|}{ Analysis of Coefficients in the Model } \\
\hline Factor & $\begin{array}{l}\text { Coefficient } \\
\text { Estimate }\end{array}$ & $\begin{array}{l}\text { Degrees of } \\
\text { Freedom }\end{array}$ & Standard Error & $\begin{array}{c}\mathrm{t}-\text { Value } \\
\left(\mathrm{H}_{0}: \beta=0\right)\end{array}$ & $\mathrm{p}$-Value \\
\hline Intercept & 1.3507 & 1 & 0.0279753 & \multicolumn{2}{|c|}{$\therefore \therefore \therefore \therefore \therefore: \therefore: \because \therefore \because \therefore: \therefore$} \\
\hline c & -0.0979668 & 1 & 0.0279753 & -3.50191 & 0.0172 \\
\hline $\mathrm{E}$ & 0.129932 & 1 & 0.0279753 & 4.64454 & 0.0056 \\
\hline & $\begin{array}{r}\text { Fina } \\
\text { Average } D\end{array}$ & $\begin{array}{l}\text { tion in Te } \\
y \text { Time })=\end{array}$ & $\begin{array}{l}\text { of Actual Fact } \\
85-0.00178 \mathrm{C}\end{array}$ & $\begin{array}{l}\text { ors: } \\
+0.0130 \mathrm{E}\end{array}$ & \\
\hline
\end{tabular}


Table 4

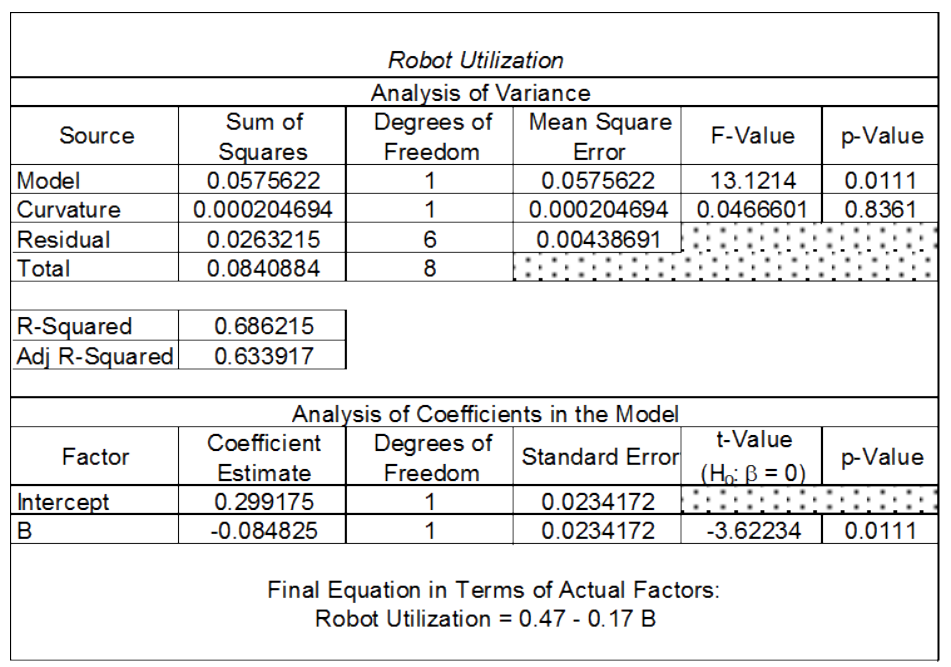


Table 5

\begin{tabular}{|c|c|c|c|c|c|}
\hline \multicolumn{6}{|c|}{ Vehicle Moves per Hour } \\
\hline \multicolumn{6}{|c|}{ Analysis of Variance } \\
\hline Source & $\begin{array}{l}\text { Sum of } \\
\text { Squares }\end{array}$ & $\begin{array}{l}\text { Degrees of } \\
\text { Freedom }\end{array}$ & $\begin{array}{c}\text { Mean Square } \\
\text { Error }\end{array}$ & F-Value & $\mathrm{p}$-Value \\
\hline Model & 0.000983434 & 2 & 0.000491717 & 29.1112 & 0.0018 \\
\hline Curvature & $3.59342 \mathrm{E}-06$ & 1 & $3.59342 \mathrm{E}-06$ & 0.212742 & 0.6640 \\
\hline Residual & 0.000084455 & 5 & 0.000016891 & \multicolumn{2}{|c|}{ 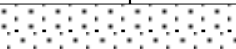 } \\
\hline Total & 0.00107148 & 8 & \multicolumn{3}{|c|}{ a: : : : : : : : : : } \\
\hline \multicolumn{6}{|c|}{\begin{tabular}{|l|l|}
\multicolumn{2}{|c|}{$\mid$} \\
R-Squared & 0.920914 \\
\end{tabular}} \\
\hline Adj R-Squared & 0.88928 & & & & \\
\hline \multicolumn{6}{|c|}{ Analysis of Coefficients in the Model } \\
\hline Factor & $\begin{array}{l}\text { Coefficient } \\
\text { Estimate }\end{array}$ & $\begin{array}{l}\text { Degrees of } \\
\text { Freedom }\end{array}$ & Standard Error & $\begin{array}{c}\mathrm{t}-\text { Value } \\
\left(\mathrm{H}_{0}: \beta=0\right)\end{array}$ & $\mathrm{p}$-Value \\
\hline Intercept & 0.0323615 & 1 & 0.00145306 & \multicolumn{2}{|c|}{$\because \therefore: \because: \because: \therefore: \therefore: \because$} \\
\hline $\mathrm{B}$ & 0.00961556 & 1 & 0.00145306 & 6.61747 & 0.0012 \\
\hline E & -0.00551999 & 1 & 0.00145306 & -3.79888 & 0.0126 \\
\hline \multicolumn{6}{|c|}{$\begin{array}{l}\text { Final Equation in Terms of Actual Factors: } \\
1 /(\text { Vehicle Moves per Hour })=0.024+0.019 \mathrm{~B}-5.520 \mathrm{E}-04 \mathrm{E}\end{array}$} \\
\hline
\end{tabular}


Table 6

\begin{tabular}{|c|c|c|c|c|c|c|c|c|c|}
\hline \multicolumn{10}{|c|}{ SCHEME B: CENTRAL STORAGE } \\
\hline \multirow{2}{*}{\multicolumn{2}{|c|}{ Experimental Trial }} & \multicolumn{5}{|c|}{ Factor } & \multicolumn{3}{|c|}{ Response } \\
\hline & & A & B & C & D & $E$ & & & \\
\hline $\begin{array}{c}\text { Standard } \\
\text { Order }\end{array}$ & Run Order & $\begin{array}{c}\text { Number of } \\
\text { Foups per } \\
\text { VO Port } \\
(\#)\end{array}$ & $\begin{array}{c}\text { Tool } \\
\text { Process } \\
\text { Time } \\
\text { (lots } / \mathrm{hr} \text { ) }\end{array}$ & $\begin{array}{l}\text { Vehicle } \\
\text { Speed } \\
\text { (ft/min) }\end{array}$ & $\begin{array}{c}\text { Stocker } \\
\text { Cycle Time } \\
(\mathrm{sec})\end{array}$ & $\begin{array}{c}\text { Number of } \\
\text { Tools in Bay } \\
\{\#) \\
\end{array}$ & $\begin{array}{c}\text { Robot } \\
\text { Utilization } \\
\\
(\%)\end{array}$ & $\begin{array}{c}\text { Moves per } \\
\text { Hour } \\
\text { (moves/hr) }\end{array}$ & $\begin{array}{c}\text { Average } \\
\text { Delivery } \\
\text { Time } \\
\text { (min) }\end{array}$ \\
\hline 1 & 5 & 1 & 0.5 & 110 & 18.0 & 30 & 0.582 & 58.024 & 4.623 \\
\hline 2 & 1 & 5 & 0.5 & 110 & 13.0 & 10 & 0.285 & 39.404 & 4.229 \\
\hline 3 & 8 & 1 & 1.5 & 110 & 13.0 & 30 & 0.216 & 29.896 & 4.885 \\
\hline 4 & 6 & 5 & 1.5 & 110 & 18.0 & 10 & 0.200 & 20.024 & 4.272 \\
\hline 5 & 3 & 1 & 0.5 & 220 & 18.0 & 10 & 0.397 & 39.448 & 3.103 \\
\hline 6 & 2 & 5 & 0.5 & 220 & 13.0 & 30 & 0.427 & 59.092 & 4.549 \\
\hline 7 & 7 & 1 & 1.5 & 220 & 13.0 & 10 & 0.146 & 20.024 & 3.012 \\
\hline 8 & 4 & 5 & 1.5 & 220 & 18.0 & 30 & 0.300 & 29.988 & 3.785 \\
\hline 9 & 9 & 3 & 1.0 & 165 & 15.5 & 20 & 0.286 & 33.100 & 4.037 \\
\hline
\end{tabular}


Table 7

\begin{tabular}{|c|c|c|c|c|c|}
\hline \multicolumn{6}{|c|}{ Average Delivery Time } \\
\hline \multicolumn{6}{|c|}{ Analysis of Variance } \\
\hline Source & $\begin{array}{l}\text { Sum of } \\
\text { Squares }\end{array}$ & $\begin{array}{l}\text { Degrees of } \\
\text { Freedom }\end{array}$ & \begin{tabular}{|c|} 
Mean Square \\
Error
\end{tabular} & F-Value & $p$-Value \\
\hline Model & 0.195165 & 2 & 0.0975824 & 12.9365 & 0.0106 \\
\hline Curvature & $7.16543 \mathrm{E}-05$ & 1 & $7.16543 \mathrm{E}-05$ & \multirow{2}{*}{\multicolumn{2}{|c|}{$\therefore: \therefore: \because: \because: \vdots$}} \\
\hline Residual & 0.0377161 & 5 & 0.00754321 & & \\
\hline Total & 0.232953 & 8 & \multicolumn{3}{|l|}{$\therefore \therefore \therefore \therefore \therefore:$} \\
\hline \multicolumn{2}{|c|}{\begin{tabular}{|l|l|}
\multicolumn{2}{|l|}{} \\
\end{tabular}} & & & & \\
\hline Adj R-Squared & 0.773264 & & & & \\
\hline \multicolumn{6}{|c|}{ Analysis of Coefficients in the Model } \\
\hline Factor & $\begin{array}{l}\text { Coefficient } \\
\text { Estimate }\end{array}$ & $\begin{array}{l}\text { Degrees of } \\
\text { Freedom }\end{array}$ & Standard Error & $\begin{array}{c}t-\text { Value } \\
\left(\mathrm{H}_{0}: \beta=0\right)\end{array}$ & $\mathrm{p}$-Value \\
\hline Intercept & 1.38652 & 1 & 0.0307067 & \multicolumn{2}{|c|}{$\therefore: \therefore: \therefore: \because \because \because \because \because$} \\
\hline $\mathrm{C}$ & -0.116292 & 1 & 0.0307067 & -3.78718 & 0.0128 \\
\hline $\mathrm{E}$ & 0.104268 & 1 & 0.0307067 & 3.39561 & 0.0193 \\
\hline
\end{tabular}


Table 8

Robot Utilization

\begin{tabular}{|c|c|c|c|c|c|}
\hline \multicolumn{6}{|c|}{ Robot Utilization } \\
\hline \multicolumn{6}{|c|}{ Analysis of Variance } \\
\hline Source & $\begin{array}{l}\text { Sum of } \\
\text { Squares }\end{array}$ & $\begin{array}{l}\text { Degrees of } \\
\text { Freedom }\end{array}$ & $\begin{array}{c}\text { Mean Square } \\
\text { Error }\end{array}$ & F-Value & $p$-Value \\
\hline Model & 1.26273 & 3 & 0.420909 & 110.987 & 0.0003 \\
\hline Curvature & 0.00041495 & 1 & 0.00041495 & 0.109416 & 0.7574 \\
\hline Residual & 0.0151697 & 4 & 0.00379242 & & \\
\hline Total & 1.27831 & 8 & & & \\
\hline R-Squared & 0.988129 & & & & \\
\hline Adj R-Squared & 0.979226 & & & & \\
\hline \multicolumn{6}{|c|}{ Analysis of Coefficients in the Model } \\
\hline Factor & $\begin{array}{l}\text { Coefficient } \\
\text { Estimate }\end{array}$ & $\begin{array}{c}\text { Degrees of } \\
\text { Freedom }\end{array}$ & Standard Error & $\begin{array}{c}\mathrm{t}-\text {-Value } \\
\left(\mathrm{H}_{0}: \beta=0\right)\end{array}$ & $p$-Value \\
\hline Intercept & 1.8915 & 1 & 0.0217727 & $\because \therefore: \therefore: \therefore$ & $\because \therefore: \therefore$ \\
\hline$B$ & 0.316147 & 1 & 0.0217727 & 14.5203 & 0.0001 \\
\hline $\mathrm{D}$ & -0.151571 & 1 & 0.0217727 & -6.96148 & 0.0022 \\
\hline $\mathrm{E}$ & -0.186865 & 1 & 0.0217727 & -8.58253 & 0.0010 \\
\hline
\end{tabular}

Final Equation in Terms of Actual Factors:

$1 /$ [Square Root(Robot Utilization $)]=2.573+0.632 \mathrm{~B}-0.0606 \mathrm{D}-0.0187 \mathrm{E}$ 
Table 9

\begin{tabular}{|c|c|c|c|c|c|}
\hline \multicolumn{6}{|c|}{ Vehicle Moves per Hour } \\
\hline \multicolumn{6}{|c|}{ Analysis of Variance } \\
\hline Source & $\begin{array}{l}\text { Sum of } \\
\text { Squares }\end{array}$ & $\begin{array}{l}\text { Degrees of } \\
\text { Freedom }\end{array}$ & $\begin{array}{c}\text { Mean Square } \\
\text { Error }\end{array}$ & F-Value & $\mathrm{p}$-Value \\
\hline Model & 0.0131794 & 2 & 0.0065897 & 1071.02 & $<0.0001$ \\
\hline Curvature & $2.60237 \mathrm{E}-06$ & 1 & 2.60237E-06 & 0.422964 & 0.5442 \\
\hline Residual & $3.07636 \mathrm{E}-05$ & 5 & $6.15271 \mathrm{E}-06$ & & \\
\hline Total & 0.0132128 & 8 & $\because \because \because \because \because \because \because:$ & $\because \because \because \because:$ & $\because \because: \because$ \\
\hline R-Squared & 0.997671 & & & & \\
\hline Adj R-Squared & 0.99674 & & & & \\
\hline \multicolumn{6}{|c|}{ Analysis of Coefficients in the Model } \\
\hline Factor & $\begin{array}{l}\text { Coefficient } \\
\text { Estimate }\end{array}$ & $\begin{array}{l}\text { Degrees of } \\
\text { Freedom }\end{array}$ & Standard Error & $\begin{array}{c}\mathrm{t} \text {-Value } \\
\left(\mathrm{H}_{0}: \beta=0\right)\end{array}$ & $\mathrm{p}$-Value \\
\hline Intercept & 0.4152 & 1 & 0.000876977 & $\therefore \therefore \therefore \therefore:$ & $\because \therefore \therefore: \therefore$ \\
\hline$B$ & 0.0349119 & 1 & 0.000876977 & 39.8093 & $<0.0001$ \\
\hline $\mathrm{E}$ & -0.0207023 & 1 & 0.000876977 & -23.6065 & $<0.0001$ \\
\hline \multicolumn{6}{|c|}{$\begin{array}{l}\text { Final Equation in Terms of Actual Factors: } \\
\left.\text { (Vehicle Moves per Hour }{ }^{25}\right)^{25}=0.387+0.0698 \mathrm{~B}-0.00207 \mathrm{E}\end{array}$} \\
\hline
\end{tabular}




\section{Paper: “A Simulation Based Experiment for Comparing AMHS Performance in a Semiconductor Fabrication Facility”}

\section{Figure Captions}

FIGURE 1: The layout of the distributed storage system (a) and the central storage system (b). The $\mathrm{X}$ on the track indicate the tool I/O and stocker I/O.

FIGURE 2: Definitio of stocker robot cycles.

FIGURE 3: Half normal probability plots for the distributed storage system for each of the three response variables.

FIGURE 4: Half normal probability plots for the central storage system for each of the three response variables.

FIGURE 5: Response surface of the average delivery time response for the distributed storage system.

FIGURE 6: Main effect plot with regard to the robot utilization response for the distributed storage system.

FIGURE 7: Response surface of the vehicle moves per hour response for the distributed storage system.

FIGURE 8: Response surface of the average delivery time response for the central storage system.

FIGURE 9: Response surface of the robot utilization response for the central storage system.

FIGURE 10: Response Surface of the vehicle moves per hour response for the central storage system. 
Figure 1

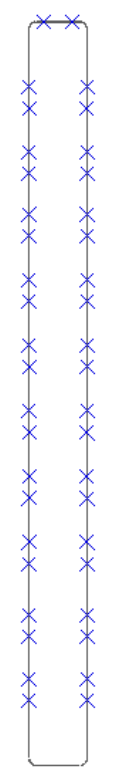

(a)

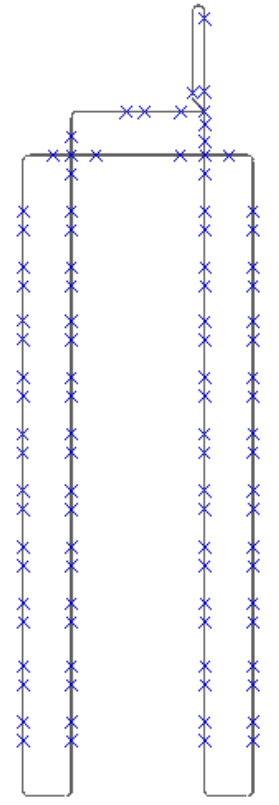

(b) 
Figure 2

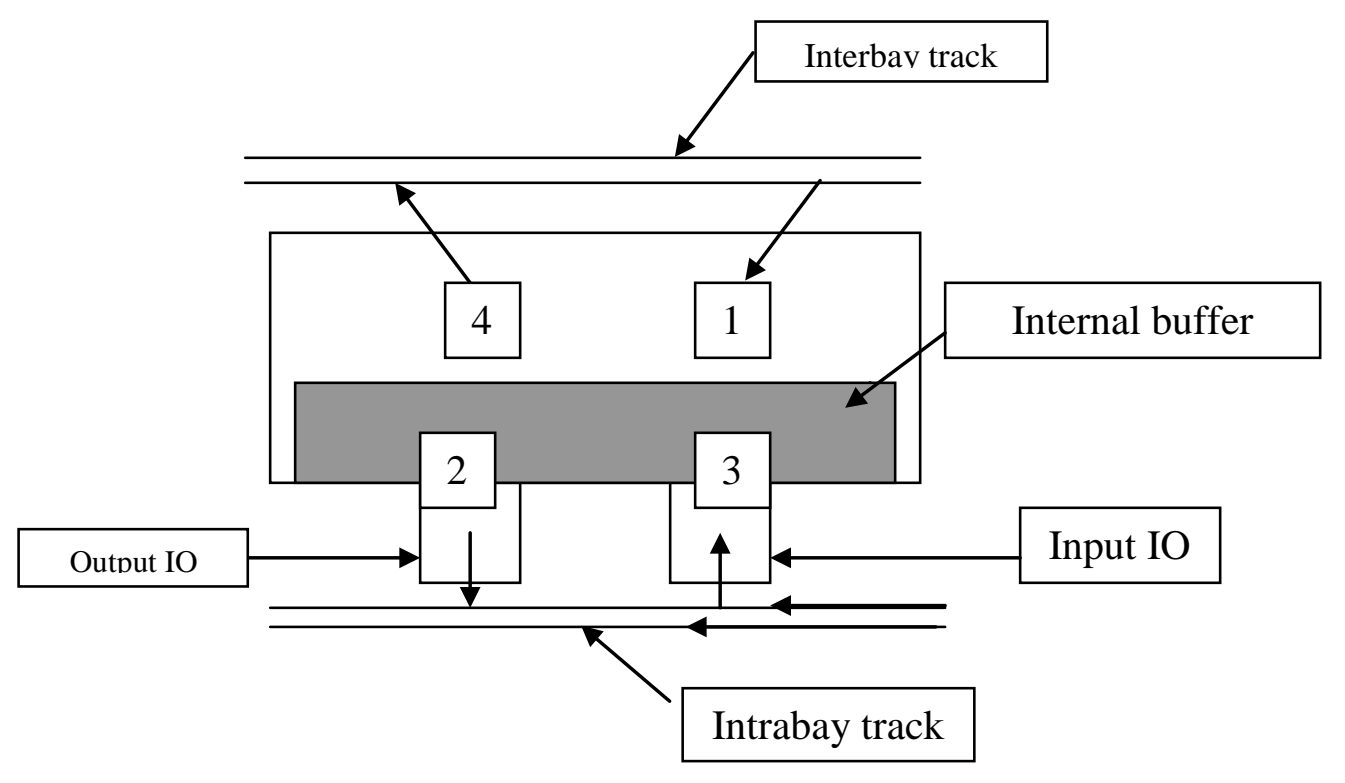




\section{Figure 3}
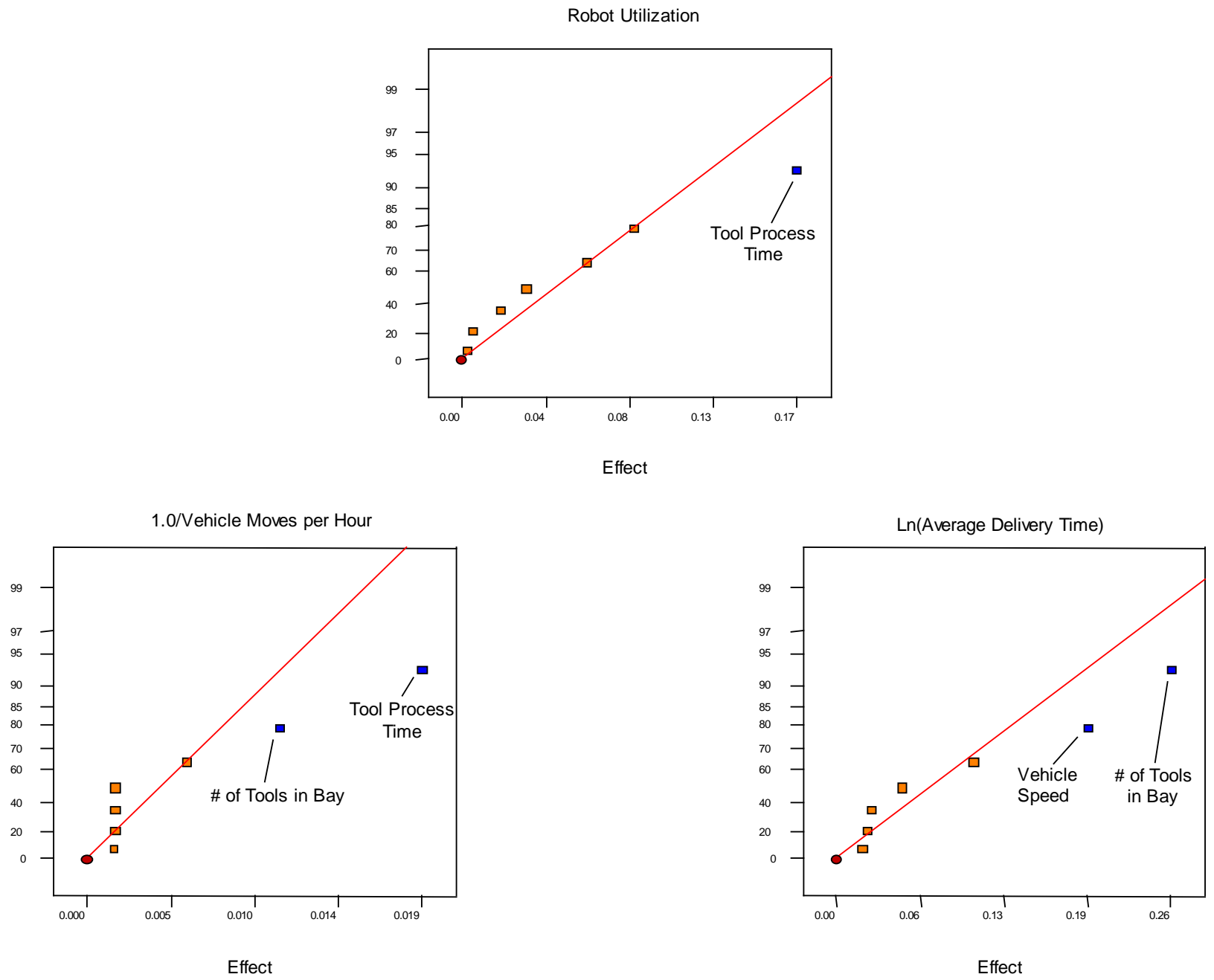
Figure 4
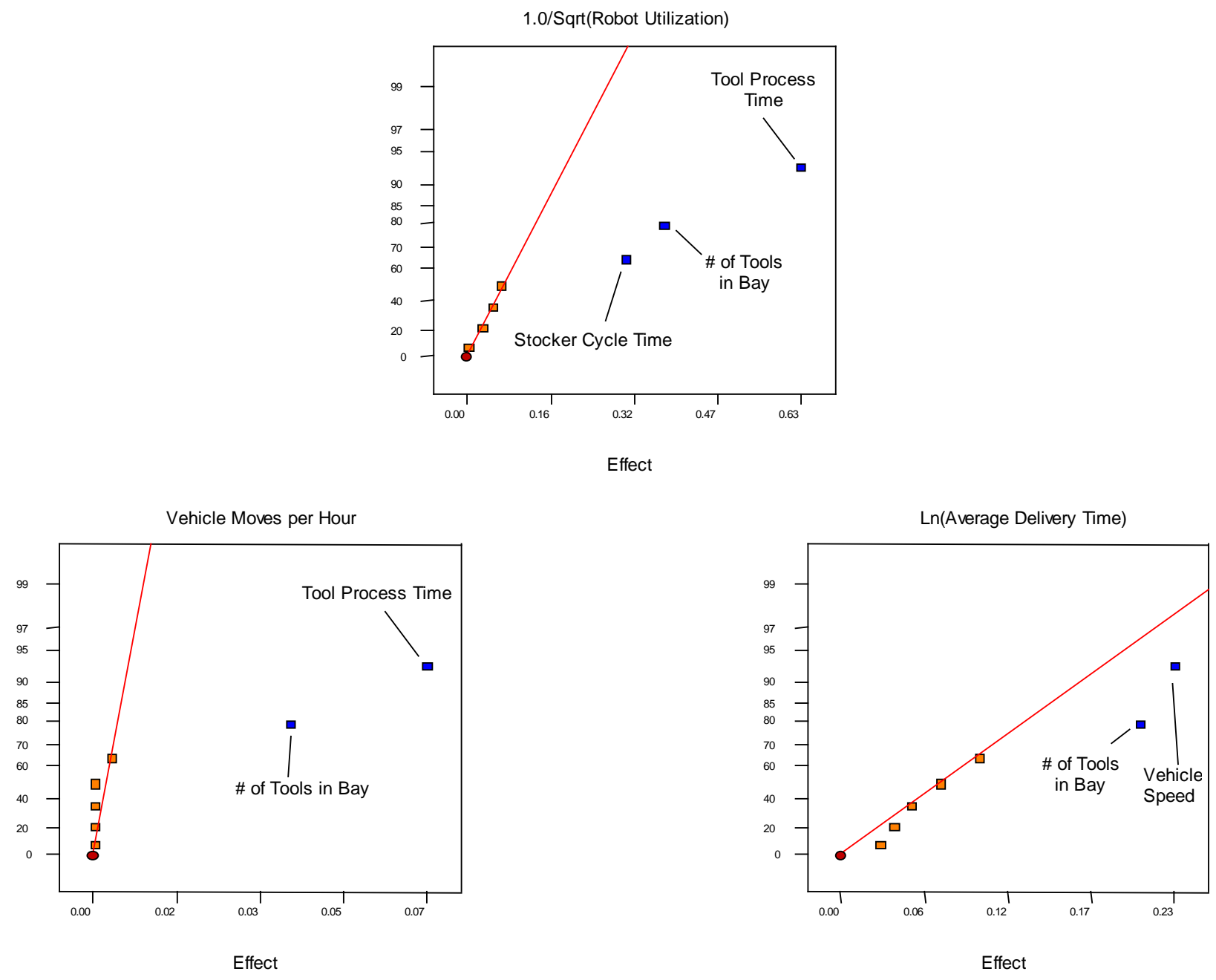
Figure 5

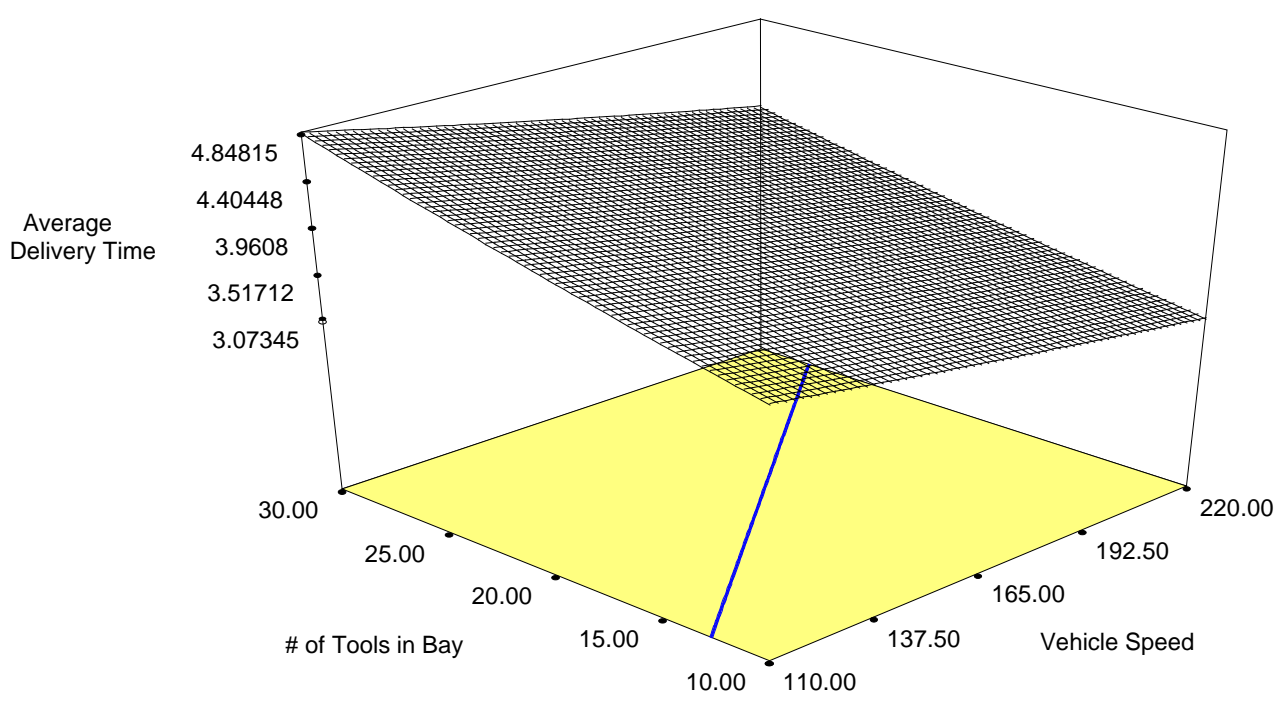


Figure 6

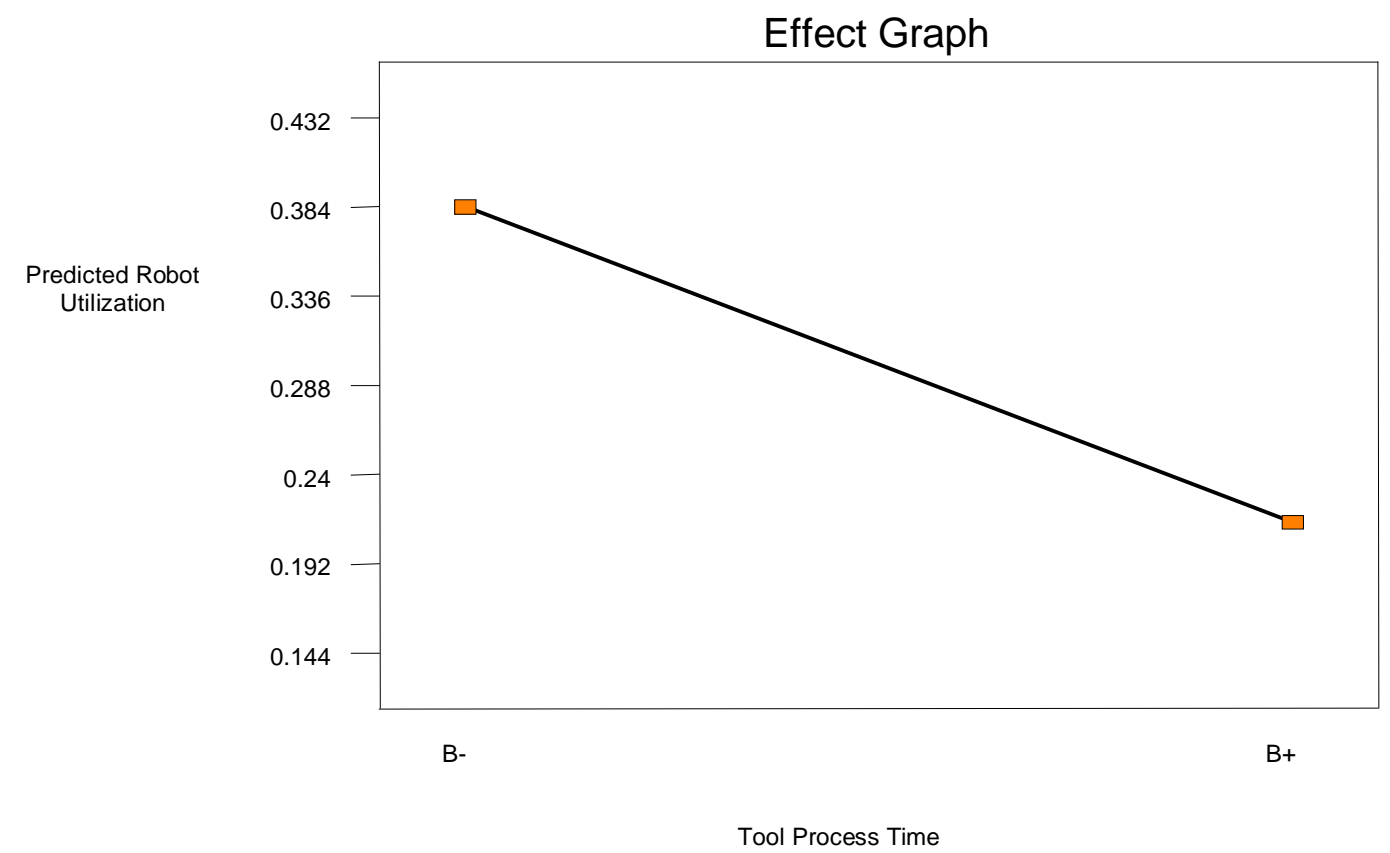




\section{Figure 7}

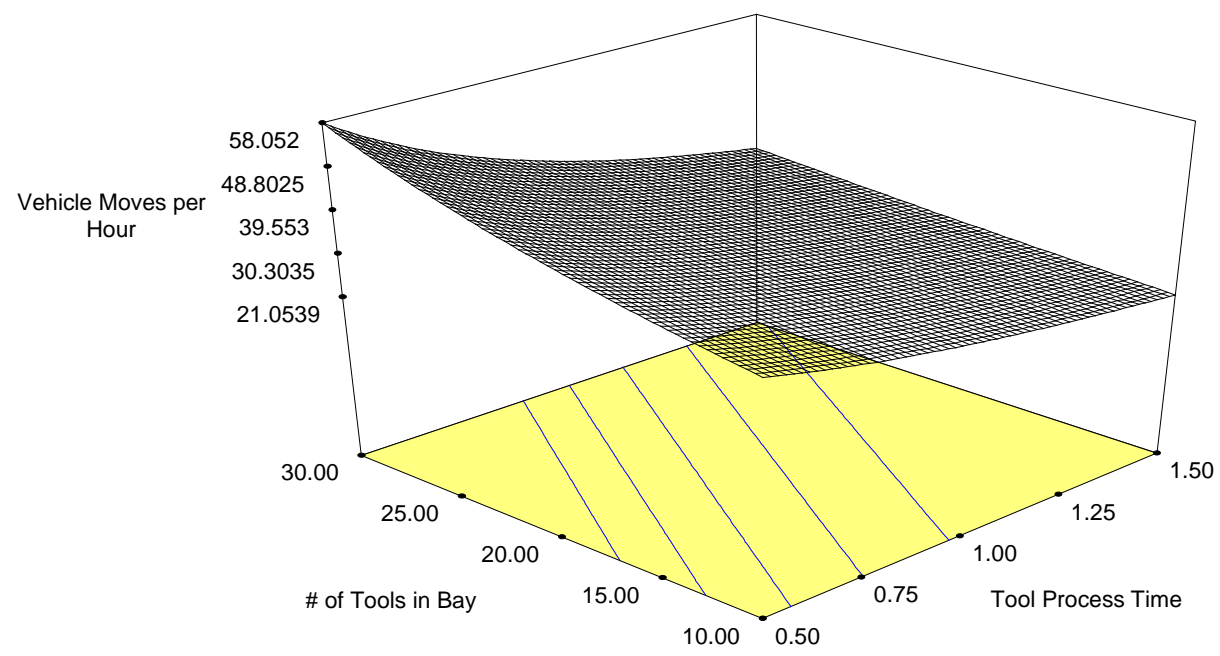




\section{Figure 8}

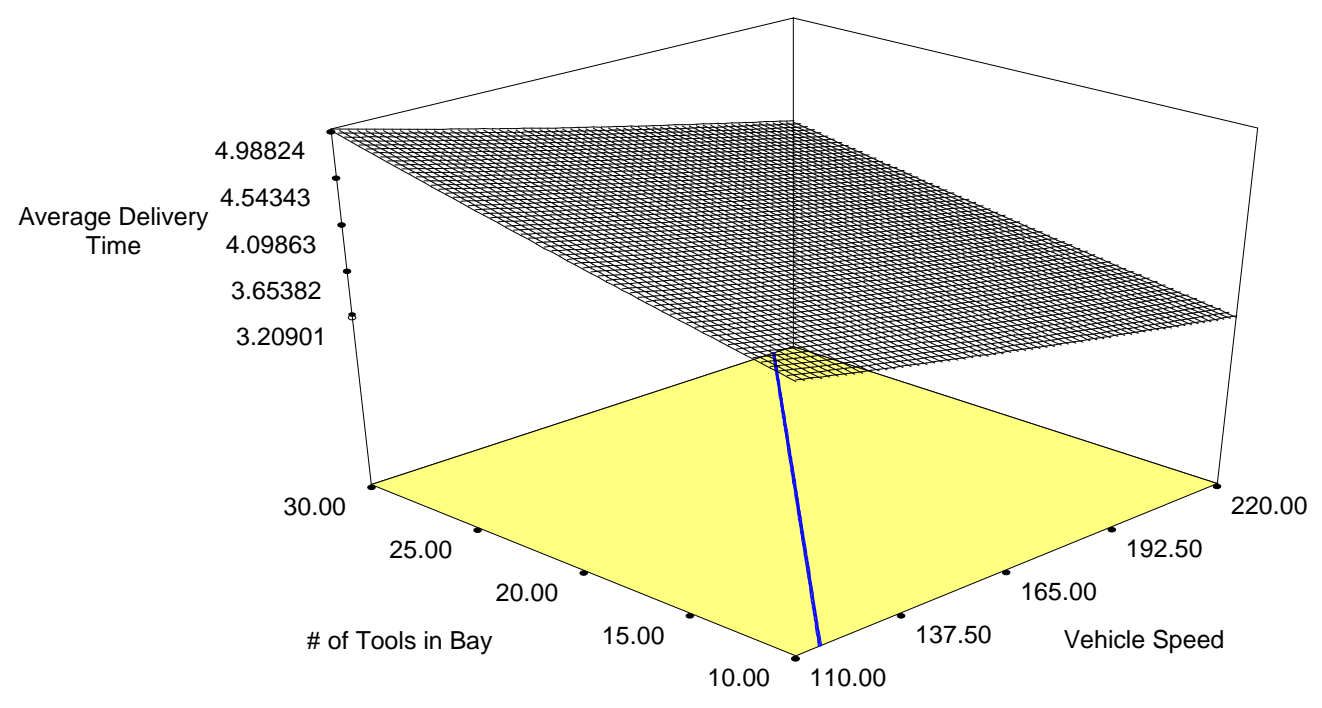




\section{Figure 9}

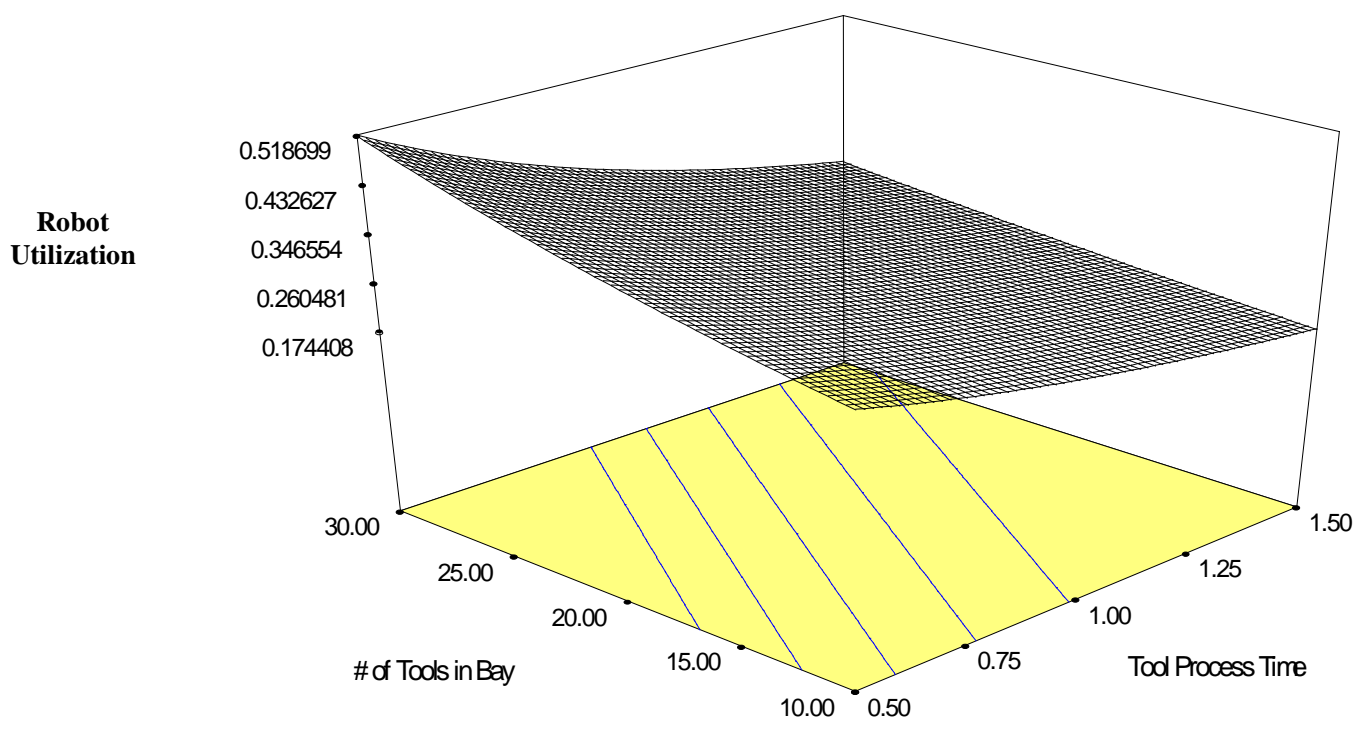


Figure 10

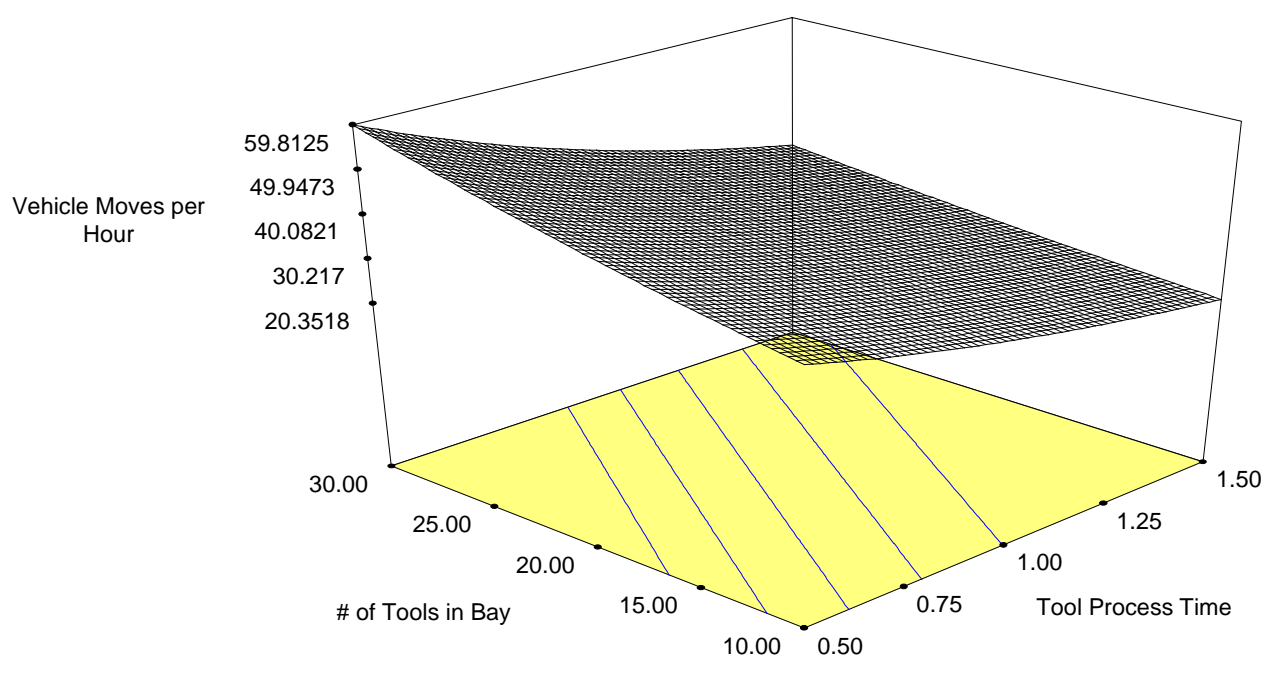

